\title{
Cuando las clases veloces: la importancia de lo sagrado personal
}

Emma Harris

Conocí a Pere Rovira por primera vez en la primavera del 2000, cuando estaba cursando segundo de Filología Hispánica. Me había matriculado en la asignatura de Modernismo y Fin de Siglo que él impartía los jueves y viernes de 17-19h. El horario no era el más oportuno — me imagino que para él tampoco — porque me coincidía con otra clase y, al vivir fuera de la ciudad, me complicaba la vuelta a casa. Aun así, pocos alumnos nos saltábamos las clases del profesor Rovira porque la melodía de sus palabras — muy medidas - nos envolvía y transportaba a la época en cuestión. Volvimos a coincidir la siguiente primavera en Poesía romántica y, ya en cuarto, en Literatura espańola IV, los jueves y viernes de 10-12 de la mańana.

De las tres materias, la que más me cautivó y ha dejado una huella permanente en mis estudios posteriores es, sin duda, Literatura espańola IV. Con el núcleo de la asignatura, el grupo de Barcelona o Generación de los 50, había entrado en contacto el cuadrimestre anterior bajo la tutela del ya difunto Jordi Jové que había propuesto la lectura de una parte de las Memorias de Carlos Barral. A través de las páginas que constituyen los tres volúmenes de las vicisitudes terrestres y marítimas del poeta-editor-marinero, van desfilando personalidades de la época: su socio Víctor Seix, arrollado por un tranvía conducido por Adolf Hitler — un nombre aún en boga en los ańos tras la contienda mundial_-; Alfonso Costafreda; Jaime Gil de Biedma; Gabriel Ferrater, cuya partida de este mundo se plasma con cierto detalle...

Teniendo en cuenta la trayectoria académica del propio Rovira que, en Modernismo y Fin de Siglo, había detallado los aciertos de las Flores del Mal de Baudelaire en la configuración estética del movimiento finisecular, no podía sorprender que entregara la batuta generacional a una de las figuras que iba a desfilar por las clases de Literatura IV. 
Así, mientras mis compañeras que no habían coincidido unos meses antes con Barral se debatían sobre si era Biezma o Biedma, asistí a la coronación de una figura que había tenido tanto protagonismo en la formación de Pere Rovira, y que él analizó en su tesis doctoral: La poesía de Jaime Gil de Biedma, recogida posteriormente en un ensayo ${ }^{1}$.

La influencia fundamental, a mi parecer, del Grupo de Barcelona y, por consiguiente, de Jaime Gil de Biedma en la dirección que han seguido ciertas vertientes de la creación poética posterior, y aun la propia obra de Rovira, se recoge al principio del primer capítulo de la obra antes citada: la sacralización del mito personal. Para ello, Rovira recoge la afirmación de su maestro y se refiere a este proceso con las siguientes palabras:

"El tema fundamental de toda la poesía moderna — afirma Jaime Gil de Biedma— es intentar explicar la relación con lo sagrado personal". Son palabras un tanto sorprendentes en boca de un poeta en el que lo sagrado entendido como experiencia religiosa no aparece jamás. Pero esta misma ausencia certifica la coherencia de la frase: la historia de la poesía moderna tiene en su base el intento de llenar el hueco dejado por la muerte de Dios, y es precisamente la falta de un principio sagrado universal lo que provoca la vuelta del poeta moderno a lo sagrado personal. Al sucumbir la explicación religiosa del mundo, la poesía recupera su papel de recurso mítico: cuando el mundo da la espalda a lo sagrado, la poesía lo reivindica. (...) todo tiene su precio: la muerte de Dios dejó al hombre solo ante la muerte y, por lo tanto, ante la necesidad de encontrar otro sentido para la vida. Antes, la explicación estaba en lo religioso, ahora el hombre está reducido a sí mismo y ha de encontrar su sentido en la propia experiencia. De ahí el reencuentro de poesía y sacralidad (...).

Como señala Rovira, era difícil validar la existencia de una figura sacra más allá del propio ser, sobre todo en un entorno bélico como el que había forjado las personalidades del Grupo de Barcelona. Si bien Jaime Gil de Biedma había pasado la contienda lejos de la capital catalana, los efectos del encuentro armado vertebraban cada rincón de la existencia. De ahí la concentración epicúrea en el yo, en ese placer como bien supremo. Y ese bienestar depende, como indica Rovira, de la propia experiencia y, en este caso, de una poesía de la propia experiencia. Difícilmente Dios podrá resucitarse de esa muerte que desencadena la necesidad de reunir la lírica con la sacralidad de la que nos habla Rovira, y es por eso, a mi parecer, que en la creación poética castellana posterior a Gil de Biedma predomina lo que Rovira denomina lo sagrado personal, que no es más que la consagración del yo en ausencia de una divinidad estable.

En la línea de su maestro e, incluso, de sus congéneres, aunque, en el campo castellano, más jóvenes, Rovira es un vitalista, un experimentador, un epicúreo cuya recom-

1. Pere Rovira Planas: La poesía de Jaime Gil de Biedma. Editorial Atrio (La razón poética. Atrio Ensayo), Granada, $2005^{2}$. En adelante La poesía. 
pensa existencial se halla en ese placer como bien supremo. En el prólogo a su poesía completa, el mismo autor afirma:

Junts els meus llibres són capítols d'un llibre nou, de la mateixa manera que les experiències que me’ls van fer escriure són capítols de la meva vida ${ }^{2}$.

Compárese al respecto lo que Rovira señaló acerca del rol de la producción poética de Biedma:

La poesía ya no es un modo placentero de cambiar la mente del lector, ahora sirve a las necesidades de conocimiento y expresión del poeta. La alianza de pensamiento y emoción, por la índole misma del desplazamiento del punto de atención en la poesía romántica, no puede concretarse en el didactismo. Es verdad que el poeta romántico es un faro, pero, como en el famoso poema de Cernuda, su mensaje es un soliloquio, pues sólo el soliloquio puede garantizar la integridad emocional. No es adoctrinar lo que cuenta, sino ofrecer un testimonio auténtico de la experiencia personal ${ }^{3}$.

Obsérvese que se refiere a los líricos románticos, tan controvertidos, que desacralizaron la figura poética con la asociación entre el yo real y la voz de sus composiciones, aunque hueca de experiencia real. Cuando pensamos en Bécquer, la naturaleza vacua de las ráfagas de tiniebla que cruzan algunas de sus leyendas, poco tiene que ver con lo que Rovira resume bajo ese ofrecimiento de "un testimonio auténtico de la experiencia personal". La experiencia poética necesita crear la ilusión de un vínculo con un conocimiento personal para que haya verdadero aprendizaje e integridad emocional; para que se venere ese mito personal sacralizado que está en las venas de la poesía medio secular y la producción posterior, incluyendo la del propio Rovira. Sin embargo, como explica el mismo autor en la Poética y poesía publicada por la Fundación Juan March en Madrid en 2016:

La poesía es un comentario, una crítica o una invención de la vida, precisamente por ese carácter suyo, no puede ser una trascripción esclava de la vida superficial. La vida sí es esclava de ella misma; la poesía no, entre otras cosas porque puede corregirse. Se supone que escribo poemas porque quiero y para que alguien los lea, y he de pensar, por tanto, en el primer lector que tendrán y en el que los leerá de una manera más interesada, que, claro está, soy yo.

Por lo tanto, he de procurar no hacerme trampas. Ya se sabe que una de las peores trampas que un escritor puede hacer, a sí mismo y a los demás, es no ser cuidadoso escribiendo, tan cuidadoso como pueda. Pero hay otras trampas. Creo que la poesía

2. "Juntos mis libros son capítulos de un libro nuevo, del mismo modo en que las experiencias que me los suscitaron son capítulos de mi vida”. Pere Rovira Planas: Poesia 1979-2004. Edicions Proa, Barcelona, 2006 (edición bilingüe, DVD, Barcelona, 2011), prólogo p. 12.

3. En La poesia, pp. 20-21. 
tolera tan mal el desapego como el apego excesivo. Lamentablemente, caí alguna vez en el primero; creo que nunca he caído en el segundo .

Tal vez se pueda acusar la idea romántica del yo de estar aquejada de la enfermedad del apego excesivo del que nos habla Rovira, y que traiciona el concepto del sagrado personal nacido en la experiencia que recoge, en mi opinión, de Jaime Gil de Biedma. Por lo que respecta a ese desapego de que nos habla, el mismo autor lo resume de forma lúcida unas páginas antes en la misma publicación, cuando señala cómo parece moda hacer alarde de las limitaciones lingüísticas personales que antes siempre habían sido motivo de pudor ${ }^{5}$, y que ahora desembocan en lo que él denomina un fenómeno de automutilación verbalt. En mi experiencia, nuestro autor tampoco se condiciona a la hora de apuntar las limitaciones de la crítica en cuestiones interpretativas: durante mi cuarto curso de carrera, Pere Rovira aún compartía despacho con el profesor Jordi Jové que impartía la asignatura Teoría de la narrativa. Es, como ya he indicado, mientras cursaba esa materia que entré en contacto con las Memorias de Carlos Barral a las que me he referido al principio de este artículo. Recuerdo que durante una tutoría el profesor Jové me prestó un libro de la biblioteca de Pere, y que era obra de la pluma de una crítica conocida sobre el Grupo de los 50. No obstante, sin lugar a dudas, el aparato analítico más interesante del volumen era el que estaba escrito en bolígrafo en los márgenes, y que seguramente enlaza con los versos que cierran la composición "Poeta de medio siglo", cuya observación inteligente está muy relacionada, a mi parecer, con las antes citadas ideas del desapego y la automutilación verbal, aunque proyectadas en la esfera de la crítica literaria:

Y también es verdad que los poetas

tendemos a sentir más que la gente;

si terminamos antes, somos muertos muy lúcidos,

y si ya no escribimos, somos los más sinceros.

-Los jóvenes lo creen, y hay críticos que gozan

explicando impotencias.

A lo largo del camino que desemboca en el hallazgo de lo sagrado personal se incide en la destrucción del concepto del poeta como habitante de una torre de marfil, a la cual ya habíamos asistido en el Modernismo ${ }^{7}$. El poeta es un ciudadano más, que general-

4. Pere Rovira Planas: Poética y poesía. Fundación Juan March, Madrid, 2016, p. 21. En adelante Poética.

5. Poética, pp. 14-15.

6. Poética, p. 14.

7. Tómese como ejemplo los siguientes versos pertenecientes a Cantos de vida y esperanza de Rubén Darío:

"La torre de marfil tentó mi anhelo;/ quise encerrarme dentro de mí mismo,/ y tuve hambre de espacio y sed de cielo/ desde las sombras de mi propio abismo.// Como la esponja que la sal satura/ en el jugo del mar, fue el dulce y tierno/ corazón mío, henchido de amargura/ por el mundo, la carne y el infierno.". Obsérvese cómo abandona la torre de marfil llevado por la sed de experimentar la verdad del mundo: "la carne y el 
mente no puede ganarse la vida a base de explorar en verso los rincones de su experiencia personal. Rovira había puesto esta característica lírica de manifiesto en La poesía de Jaime Gil de Biedma:

La labor de autoconocimiento que supone la poesía moderna requiere tener las cosas claras con respecto a las relaciones entre "el poeta y la ciudad". El poeta carece de status social: no existen instituciones donde se pueda aprender el oficio ni diplomas que acrediten su dominio. Basta, en fin, pensar en que la poesía raramente es una profesión con que ganarse la vida: puede influir decisivamente en el modo de entenderla y de orientarla, pero, en lo concerniente a su sustento, el poeta está generalmente obligado al pluriempleo. ${ }^{8}$

Si bien en la mayoría de los casos no es posible sujetar la salud de la economía personal al oficio poético, tampoco hay que forzar la producción lírica en arras de una obra demasiado nutrida: si miramos la propia trayectoria poética de Pere Rovira constataremos que, aparte del volumen recopilatorio, ha publicado cinco poemarios entre cuya producción ha habido períodos de silencio creativo. En la antes citada Poética y poesía se refiere, en términos generales, a estas lagunas en cualquier labor creativa: señala la necesidad de no caer en la tentación de reducir la interpretación literaria a términos demasiado simples: aun a pesar del pluriempleo al que se refería en su ensayo sobre Gil de Biedma, no hay que convertir la producción poética en una raison d'être, que desemboque en una redacción mediocre para satisfacer la idea de una necesidad de producir determinado número de versos al año. Por eso, Rovira señala como maestros aquellos poetas, lejos de las elucubraciones de la crítica, que publicaron poco, pero meditadamente:

Los maestros a los que me refiero (...) podían presentar como una hazaña el haber escrito sólo tres libros. Uno de ellos, Jaime Gil de Biedma, solía comentar que más de un gran poeta había estropeado su obra escribiendo demasiado, hasta llegar a ser una mala imitación de sí mismo.?

Así, cierta disponibilidad hacia la producción poética, pero, en ningún momento, una obsesión por producir versos para llenar un hueco existencial y, cuando menos, económico en la vida del creador.

Por lo que respecta al tema lírico, la creación inicial de Rovira se sitúa en un momento de claro tras la tormenta verbal de los Novísimos. Y, debido a ese renacido afán de acercamiento a la experiencia, el poema tiende a veces hacia los tonos prosísticos: recuérdese

infierno”. En Rubén Darío: Azul...Cantos de vida y esperanza, edición de Álvaro Salvador, Espasa Calpe (colección Austral), Madrid $1999^{6}$.

8. Poética, p. 23.

9. Poética, pp. 22-23. 
la naturaleza en ocasiones conversacional de otros creadores experienciales como Vicente Gallego en su producción última de la década de los ochenta. ${ }^{10} \mathrm{Y}$ eso, nos señala Rovira, era la dirección correcta de la poesía que escribía entonces:

En aquel momento quizá era necesario escribir así, tras los alardes pseudovanguardistas, a menudo ininteligibles, de la llamada generación novísima. Había que devolverle a la poesía un poco de cordialidad y de trato humano, para que no la asfixiaran la verborrea y la pedantería. ${ }^{11}$

Sin embargo, advierte: calor humano sí, charlatanería sin medida no, porque, si bien los Novísimos pecaron de separarse del componente efímero asociado a la existencia que había sido frecuente en la poesía anterior, su léxico escogido nunca descendía a los fondos de lo que sería el hablar por hablar, sin medida ni musicalidad. De aquí que Rovira recalque que la poesía es "mera literatura"12 y, como tal, se rige por una serie de reglas ineludibles. En la sublimación del género, y aun en la rotura de la medida del verso y de la composición, los románticos, de nuevo, juegan un papel desfavorable. La desacralización del mundo en que vivían junto al valor profético otorgado al yo de las composiciones de algunos bardes, fueron capaces de romper los confines calculados del poema con los consiguientes inconvenientes expresivos: estructuras dilatadas de valor fluctuante. $Y$ con esa alabanza a la necesidad de contemplar muy seriamente la brevedad en cualquier trabajo lírico, regresamos a la importancia de lo sagrado personal en la configuración de la estructura poemática: la fuente de la composición medida es el éxtasis ocasional que sucede entre momentos más prosaicos. Como la existencia misma, el poema es un recorte de experiencia elevada que ocurre entre temas cotidianos que, según apunta Rovira, no tienen cabida en el poema — los atascos, las características de una vivienda... —: lo excitante, aquello que nos acerca a los dioses y que es digno de ser recordado, convive con las depresiones y el día a día. La selección de hechos destacables, dignos de constituir lo sagrado personal, radica en la capacidad de discernir experiencias de forma medida y comedida entre la mediocridad de los capítulos de la propia vida. A esta selección cuidados he asistido primero en las clases del profesor Rovira y, posteriormente, en la obra prosística y lírica del escritor Pere Rovira i Planas.

10. Tómese como ejemplo el poema "Échale a él la culpa", en donde conversa con su pareja que ha salido de fiesta y que está tardando en regresar. En Vicente Gallego: La plata de los días, Visor, Valencia, 1996.

11. Poética, p. 24.

12. Poética, p. 23. 